\title{
Experiences in Designing Personal Health Assistants for the Impending Aged Generation
}

\author{
Dina Ahmad, Andreas Komninos, Lynne Baillie \\ Glasgow Caledonian University \\ 70 Cowcaddens Rd. \\ Glasgow G4 OBA \\ +441413313095 \\ dahmad10@caledonian.ac.uk, [ako2, lba2]@gcal.ac.uk
}

\begin{abstract}
Our work aims to address the problems of designing health assistant applications that run on mobile devices. We discuss the lessons learnt through the design of a mobile application for use by $45-55$ year olds, who will be the likely users of such assistive technologies within the next decade.
\end{abstract}

\section{Categories and Subject Descriptors}

H.5.2 [User Interfaces]: Prototyping, Screen Design, Usercentred Design

\section{General Terms}

Design, Human Factors

\section{Keywords}

Mobile Application Design, Mobile Healthcare

\section{INTRODUCTION}

As people age they are more likely to suffer from age related impairments, which can be an obstacle to successful mobile device use [1]. Older adults show a reduction in the width of their visual field, their ability to see fine details and the ability to process visual information which could be problematic in using appliances and devices [2]. Given the increasing reliance of our society on mobile devices and the probability that the future aging generation will be familiar with these, the use of mobile devices to support the independence of older adults is a promising prospect worth investigating.

\section{AN INCLUSIVE DESIGN PROCESS}

The project aims to investigate how adults aged 40-55 with Presbyopia would respond to a self-diagnosis system running on their normal mobile device. This target group is particularly important and distinctly different from the current ageing population in terms of their familiarity with mobile devices and services. We employ an inclusive design process that seeks design input from focus groups of people around the target age range. Furthermore, design input from clinical personnel (nurses, doctors) is also sought, as intended users are often

\section{(C) The Author 2008 .}

Published by the British Computer Society unaware of potential issues or intentionally reluctant to admit these.

We hope that an intervention at the targeted age ranges will have several benefits for their wellbeing: First, making people aware and acceptant of mobile technologies they might need to rely on in the future. Second, helping people monitor their health and become aware of early signs of conditions, before they become serious. Third, allowing people to help peers in cases of emergency, by providing easy access to simple first aid procedures. We are currently evaluating the efficacy of our design process and impact of the software on people's lives.

\section{METHODOLOGY}

A number of experiments are under progress to evaluate and measure people's attitude towards the use of a mobile device health application to monitor their health.

The experiments involve the participation of the target group to produce a self-diagnosis application on a mobile phone. Our design methodology addresses the user interface design requirements for older adults aged 40-55 with early signs of Presbyopia. We have, from the project's conception, aimed to test our design methodology by means involving users in evaluating the effectiveness of the software on people's daily lives, over a period of time. This will be achieved by participating users in the design, design validation and trial of the application.

\subsection{Paper Prototyping}

The main purpose of the design phase is to produce the application's user interface in line with the user's needs, and to achieve this, the Paper Prototyping method was selected. The Paper Prototyping technique was chosen to give the users the opportunity to express their needs in a usable application that they may use in their daily lives.

A small number of people are needed to create a design using Paper Prototyping [4], thus, for our early stage work, 4 people within the target group have participated in creating the application user interface design in a total of two paper prototyping sessions.

The first session involved introducing the participants to the project and understanding current problems which they face using a mobile phone application. The second session focused on encouraging the users to create a design for the application using pens and papers based on scenarios addressing all the issues mentioned in the first session in using a mobile application. The participants were given paper props (a cardboard cut-out of a mobile device and blank paper pieces which were the size of the cardboard phone's screen. The participants were allowed to design screen prototypes using 
pens of all colours and try them out on the cardboard phone to see how they liked the layout. We did not intervene in any of the design decisions made by the participants.

\subsection{Design Validation}

Usability testing was selected to validate the application design. The aim of the test was to validate the application paper design's wording, layout and sequencing [3] from a new user point of view, therefore we engaged a fifth participant who was an HCI expert and has never seen the application design before

The expert participant was briefed on the project goals, asked to read four scenarios and perform each task using the paper prototypes that were created by the first group of participants. Performing the scenario tasks was completed using a Walkthrough (Think Aloud) technique, during which the participant was videotaped to capture verbal feedback and the sequence of their actions. Having analysed the evaluation session, it was noted that the use of shortcuts to navigate through the application design was found to be useful. The expert was able to find their way to complete all tasks successfully. The application wording was appropriate and understandable and the use of black text on white background made the application easy to read. The expert believed that the application's idea was very good and there is a strong possibility of them using the application in the future to monitor their health.

\section{RESULTS}

Participants in the paper prototyping stage were asked to highlight their perceptions on current mobile phone applications usability and it was found that they all have several problems with current technology. Amongst the comments received from these participants, possibly the most interesting in terms of application and UI design were the following:

- "I can not use the calendar in my mobile phone as I find the numbers too small"

- "I returned my new phone because I couldn't see people's numbers in my contacts"

- "I like browsing the internet but I don't do in my mobile phone as I find scrolling up and down the page a difficult task"

- "I have to call my son all the time to withhold my number in my mobile phone because I find it a complex function to navigate to"

During the prototyping phase, the participants established a common set of design "guidelines" which they felt were good practice in overcoming the difficulties they find when using a mobile phone application. They then agreed to use these interface design guidelines throughout the application design (see Figure 2).

The Interface Design Guidelines that were produced by the participants' group were as follows:

- Use Black text for writing

- Use a White background

- Use the number key pad as shortcuts to navigate

- Use a large, readable font

- Keep the consistency of all pages throughout the application design

- Keep the design simple

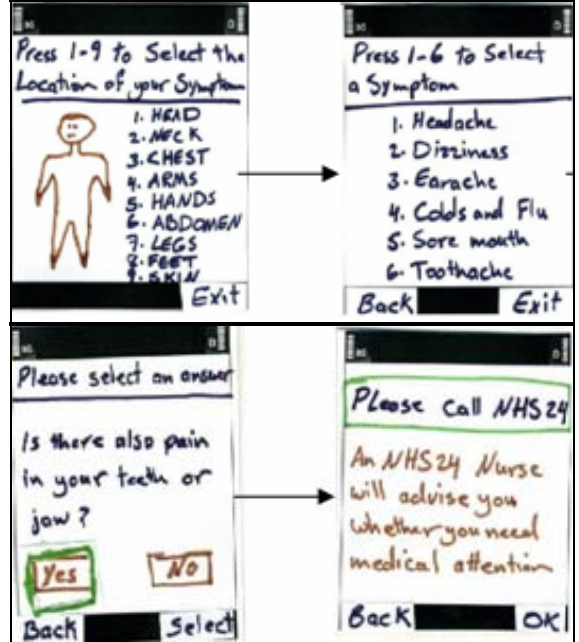

Figure 2: Screen samples from paper prototyping design sessions

\section{FUTURE WORK}

We are currently developing the application on a mobile phone using J2ME and once the development phase is completed, the application will be deployed in a number of mobile phones for a trial period. We are also in the process of validating the paper prototypes with further focus groups, in the hope of discovering additional guidelines and validating the existing set. Furthermore, discussions with a national health board that provides remote healthcare (NHS24 Scotland) are underway to establish broader scope trial of the system.

\section{REFERENCES}

[1] Arnott, J.L., Khairulla, Z., Dickinson, A., Syme, A., Alm, N., Eisma, R. \& Gregor, P. 2004, E-mail interfaces for older people, Systems, Man and Cybernetics, 2004 IEEE International Conference on, pp. 111.

[2] Hawthorn, D. 2000, Possible implications of aging for interface designers, Interacting with Computers, vol. 12, no. 5 , pp. $507-528$

[3] Shneiderman, B. (2005). Designing the User Interface. Strategies for Effective Human-Computer Interaction (4th edition). Reading, Mass.: Addison-Wesley

[4] Snyder, C. (2003) Paper prototyping: The fast and easy way to design and refine user interfaces. Morgan Kaufmann Publishers, London, 2003.

Figure 1: Derived Interface Design Guidelines 